\title{
Epithelioid hemangioendothelioma of the spine: case report and review of the literature
}

\author{
Abdulrahman Albakr ${ }^{1}$, Miranda Schell ${ }^{2}$, Brian Drew $^{3}$, Aleksa Cenic ${ }^{4}$ \\ ${ }^{1}$ Division of Neurosurgery, College of Medicine, King Saud University, Riyadh, Saudi Arabia; ${ }^{2}$ Division of Pathology, ${ }^{3}$ Division of Orthopedics, \\ ${ }^{4}$ Division of Neurosurgery, McMaster University, Hamilton, Ontario, Canada \\ Correspondence to: Dr. Aleksa Cenic. Assistant Professor Division of Neurosurgery, McMaster University, Hamilton General Hospital, McMaster \\ Clinic Wing, Room 730, 237 Barton St. E, Hamilton, Ontario L8L 2X2, Canada. Email: acenic@sympatico.ca.
}

\begin{abstract}
Epithelioid hemangioendothelioma (EHE) has been described as a rare vascular bone lesion with histological features between hemangioma and high-grade angiosarcoma. Spinal EHE is a quite rare disease with few case reports and series reported in the literature. The tumor cells are positive for vimentin, CD31and CD34, factor VIII related antigen, ERG, and FLI1. Radiological features are not specific; it may appear as an osteolytic lesion. It can present as a multifocal disease in $40 \%$ of cases. No clear correlation with age and sex; however, it is slightly more common in males. Focal neck or back pain is the most common presenting symptom. The natural history of spinal EHE is unpredictable, and currently, there is no standard of care for treatment. Treatment options include preoperative embolization, and surgical resection followed by radiotherapy and/or chemotherapy. A 34-year-old previously healthy male presented with mid-thoracic back pain. Magnetic resonance imaging (MRI) of the spine revealed a decrease in vertebral body height at T5 with an enhancing mass. He underwent T5 balloon kyphoplasty and needle vertebral body biopsy. Results of the biopsy samples were non-diagnostic. Approximately 3 months after surgery, the patient presented with unsteady gait. A subsequent MRI revealed progression of the T5 compression fracture with cord compression. The patient subsequently underwent T4-T6 bilateral posterior decompression for epidural tumor and T3-T7 posterior instrumentation with pedicle screws. Pathology of the lesion revealed EHE. The patient was started on local radiation therapy (RT). On follow-up, 3 months after the second surgery, the thoracic spinal pain had improved dramatically. Our review highlights the diagnosis, clinical presentation, and treatment of spinal EHE. Complete resection is associated with good outcome. Radiotherapy has been used in partially resected lesions. However, the role of radiotherapy as primary treatment is not yet defined. Further studies should develop a treatment algorithm for this rare tumour.
\end{abstract}

Keywords: Epithelioid hemangioendothelioma (EHE); spinal tumour; vascular tumour; radiation therapy (RT)

Submitted Dec 09, 2016. Accepted for publication Feb 14, 2017.

doi: $10.21037 /$ jss.2017.05.05

View this article at: http://dx.doi.org/10.21037/jss.2017.05.05

\section{Introduction}

Epithelioid hemangioendothelioma (EHE) is a very rare neoplasm that has been described to have histological features between hemangioma and high-grade angiosarcoma (1). Weiss et al. described it first in 1982 as a vascular neoplasm of both bone and soft tissue (2). It is commonly seen in soft tissues but can also be located in other organs such as lung, pleura, spleen, heart, liver, and bone $(3,4)$. Primary EHE of the bone is rare, and it represents only $1 \%$ of all malignant tumors of the bone (3). These tumors can be asymptomatic and discovered as an incidental finding. However, local pain is the most common presentation of spinal EHE (5).

Primary involvement of the spine is very rare, with only few case reports in the literature. Since spinal EHE is a rare condition, the ideal extent of surgical resection and the role adjuvant radiotherapy and/or chemotherapy is not 

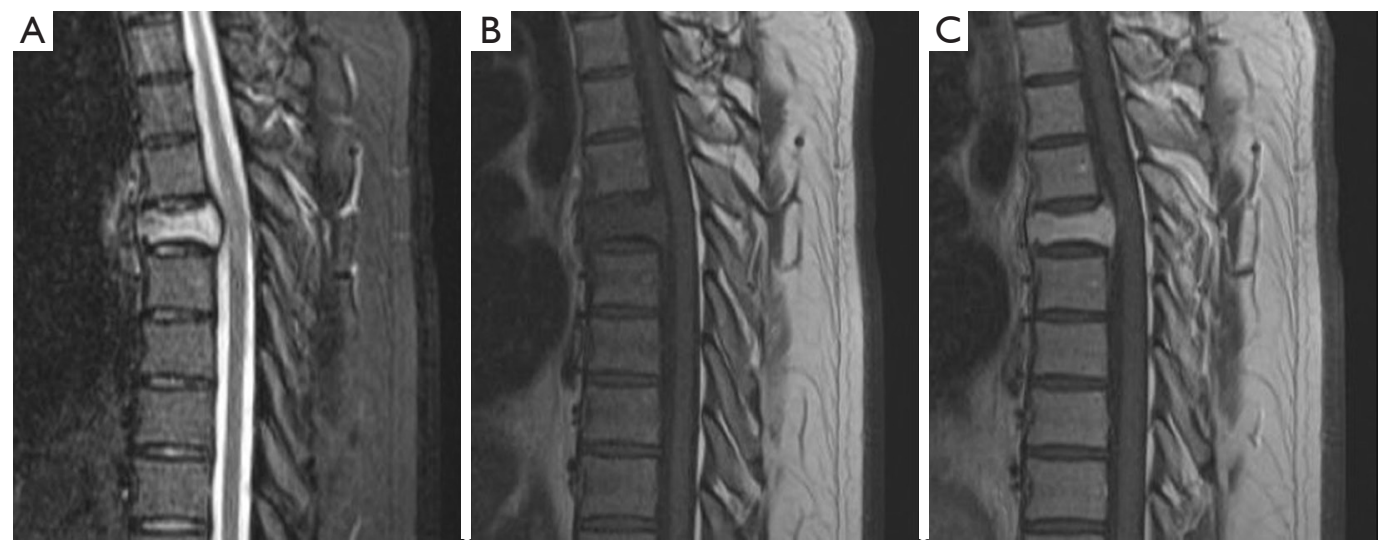

Figure 1 Magnetic resonance imaging (MRI) of the patient's thoracic spine at the first presentation. (A,B) Sagittal T2 and T1-weighted MRI demonstrating T5 compression fracture with decrease in the height of T5 vertebral body; (C) sagittal post-contrast T1-weighted image revealed an enhancing lesion replacing most of T5 vertebral body.

clear $(1,3)$. Here, we report a case of spinal EHE that underwent surgical treatment and radiotherapy.

\section{Case presentation}

A 34-year-old previously healthy man presented to the hospital with back pain following a history of trauma to the back. On examination, power was normal in all four limbs with no neurological deficits. Magnetic resonance imaging (MRI) of the spine revealed severe decrease in vertebral body height at T5 with an enhancing mass replacing most of T5 vertebral body (Figure 1). Subsequently the patient underwent a CT-guided biopsy but the sample was inconclusive. The patient continued to have significant focal back pain. For this reason, he underwent T5 balloon kyphoplasty and needle vertebral body biopsy. After the surgery, the pain improved significantly. However, results of biopsy samples were non-diagnostic.

Approximately 3 months after kyphoplasty, the patient presented with unsteady gait due to lower limb ataxia. Thereafter, the patient sustained a mechanical fall, which resulted in left lower extremity weakness. There was no bowel and bladder dysfunction. On examination, the patient had significant left lower extremity weakness. Left plantar flexion $3 / 5$, left dorsiflexion $0 / 5$, left knee flexion $2 / 5$, and left knee extension 3/5. A subsequent MRI of the spine revealed progression of the T5 compression fracture with central canal stenosis and cord compression, as well as interval progression of the enhancing lesion (Figure 2). Due to spinal cord compression, the patient was started on dexamethasone.

The patient subsequently underwent T4-T6 bilateral posterior decompression for epidural tumor and $\mathrm{T} 3-\mathrm{T} 7$ posterior instrumentation with pedicle screws. There were no intraoperative complications and his postoperative course was uneventful. Pathology of T5 vertebral body and epidural lesion (Figure 3) demonstrated a vascular tumor with cords and groups of epithelioid cells set in a myxohyaline matrix. Endothelial markers CD34 and CD31 were positive in our sample (Figure 4). The tumor was positive for ERG stain (Figure 5). Cytokeratin CK18 shows weak-moderate staining within lesional cells. Anti-pan cytokeratin (AE1/AE3), anti-cytokeratin (CAM 5.2), and epithelial membrane antigen (EMA) analyses were negative. The morphology and immunohistochemical staining pattern support the diagnosis of EHE.

After the second surgery, the patient had completed 25 fractions of local radiation therapy (RT). At the latest follow-up, approximately 3 months after the second surgery, the thoracic spinal pain had improved dramatically. The patient's neurological signs and symptoms improved as well, and he was ambulating without any gait assisting devices.

\section{Discussion}

\section{Pathology}

EHE has been described as a rare vascular bone lesion with histological features between hemangioma and highgrade angiosarcoma (1). Microscopically, the tumor cells are composed of anastomosing cords, solid nests, or round 

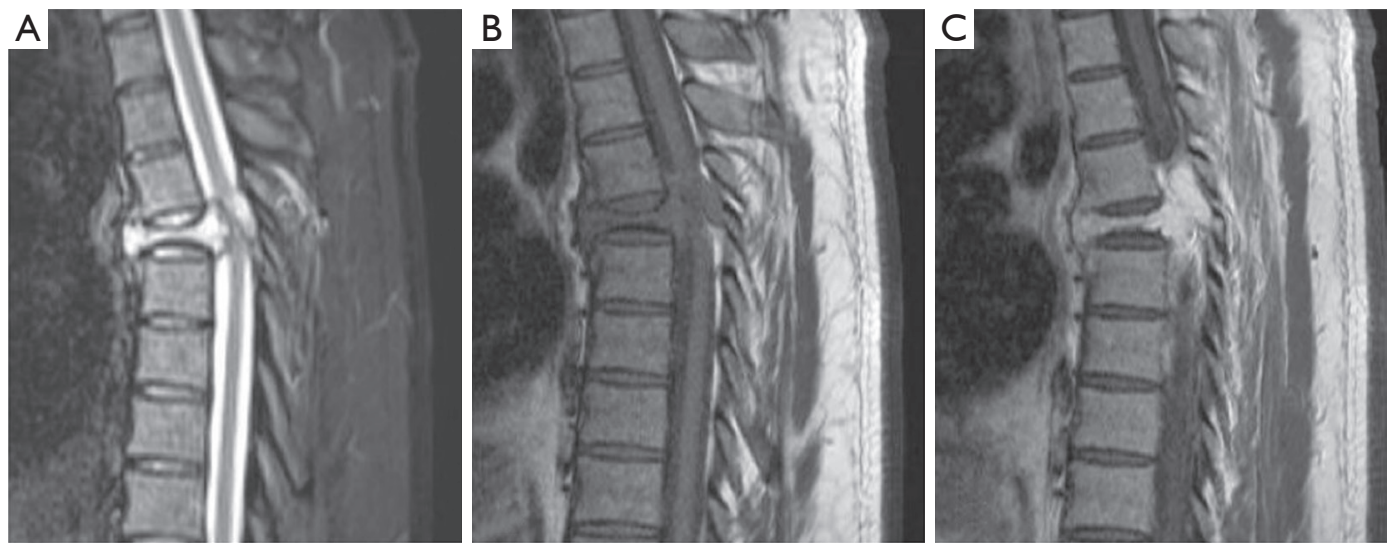

Figure 2 Magnetic resonance imaging (MRI) of the patient's thoracic spine at more recent presentation. (A,B) Sagittal T2 and T1-weighted images demonstrate interval progression of compression fracture involving T5 vertebral body with progressive cord compression and central canal stenosis, also slightly increase in signal intensity on T2-weighted image and decrease in signal intensity on T1-weighted image; (C) sagittal post-contrast T1-weighted image revealed interval progression of the enhancing tumor with severe cord compression.
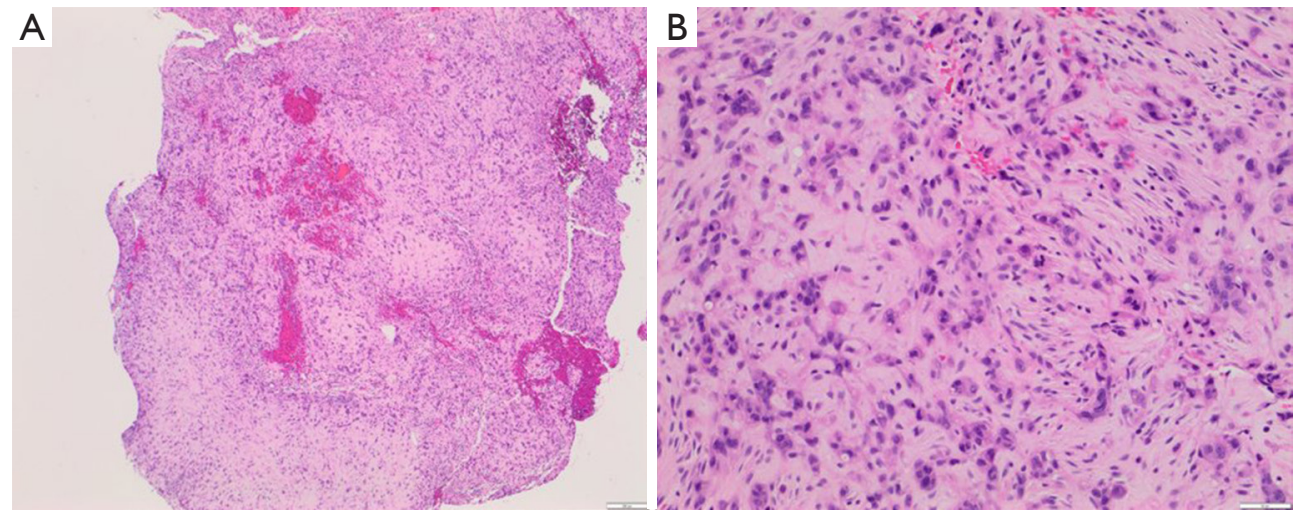

Figure 3 Histopathology of the resected mass. (A) Low-power (40x) magnification of (H\&E) stained slides demonstrating alternating areas of cellularity with prominent regions of hyalinized stroma; (B) high-power magnification (400x) shows cords and groups of epithelioid cells in a dense myxohyaline matrix. Well-formed vascular structures are not present.

eosinophilic endothelial cells (2). The lesion does not display well-formed vascular structures such as those seen in hemangioma, also it lacks the cytologic atypia seen in angiosarcoma $(2,6)$. On immunohistochemical analysis, the tumor cells are positive for vimentin, endothelial markers such as CD31and CD34, factor VIII related antigen and newer vascular markers including ERG and FLI1 (7-9). Also weak staining with cytokeratin can be seen (10). In our case, the tumor was positive for CD31 and CD34, ERG, and weakly for cytokeratins 18 (Figures 4 and 5). On gross examination, EHE has been described as "a rubbery redgray tissue" due to the vascularity of the lesion $(8,11)$. In our case, the specimen consisted of soft tissue fragments with abundant hemorrhage.

Based on the histopathological features, the differential diagnosis for such disease includes benign, intermediate and malignant vascular lesions (8). Given the appearance, metastatic carcinoma also enters into the differential diagnosis (8). A benign vascular lesion, epithelioid hemangioma, is often mistaken with EHE (12). However, unlike epithelioid hemangiomas, EHE is commonly present as large, infiltrative lesions (13). Angiosarcoma is malignant vascular tumor that can be mistaken with EHE (14). The presence of both EHE and angiosarcoma 


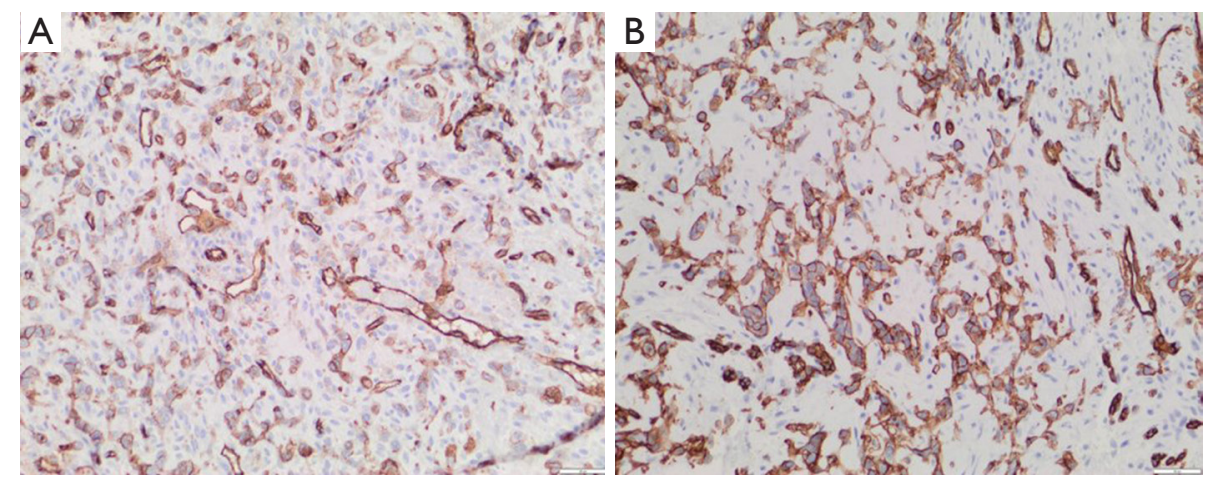

Figure 4 Immunohistochemical stain of the resected mass. (A) Tumor cells express CD31 (CD31 immunohistochemical stain, 200x magnification); (B) tumor cells express CD34 (CD34 immunohistochemical stain, 200× magnification).

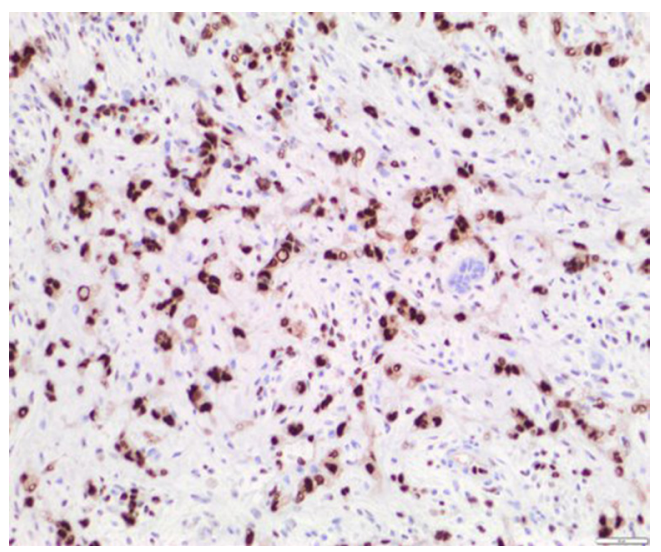

Figure 5 ERG immunohistochemical stain, 200× magnification. ERG shows nuclear staining within lesional cells. The background endothelial cells also show nuclear staining.

in a patient with cervical spine lesion has been reported in the literature (7). Histological features, such as low mitotic rate and the minimal nuclear pleomorphism have been used to distinguish EHE from angiosarcoma (15). Immunohistochemistry is often not helpful in distinguishing EHE from angiosarcoma as they both stain with CD31, CD34, factor VIII, FLI1, and ERG (16-20). However, these vascular markers are very helpful in distinguishing these lesions from other mimics, including melanoma and carcinoma $(21,22)$. Beyond morphologic assessment, EHE can be distinguished from other benign and malignant vascular lesions (including epithelioid angiosarcoma) by detection of the WWTR1-CAMTA1 gene fusion by either FISH or PCR-based methods. The use of a novel immunohistochemical stain for CAMTA1 has recently been studied $(9,23,24)$.

\section{Radiological features}

Radiographically, the findings of EHE are not specific; it can appear as an osteolytic lesion, and smaller lesions are usually well-defined, and larger lesions are ill-defined and permeative (25). The soap bubble appearance with expansion of bone has been described (8). It can present as solitary lesion in $60 \%$ of the cases or multifocal disease in $40 \%$ of the cases (16). As this disease can be multifocal at presentation, a complete skeletal survey is strongly recommended following the diagnosis of spinal EHE (16,26).

Computed tomography (CT) scan, though nondiagnostic, can be used to evaluate the degree of bony destruction (15). MRI findings of EHE are nonspecific, they include decrease in signal intensity on T1-weighted images, and isointense to slightly increase in signal intensity on T2-weighted images (13). In our patient, MRI demonstrated a lytic lesion that enhanced with gadolinium showing cord compression, and slight increase in signal intensity on $\mathrm{T} 2$-weighted images and decrease in signal intensity on T1-weighted images (Figure 2). The radiographic differential for such disease is related to the patient's age and the extent of the disease. In the elderly with multifocal disease the differential diagnosis would include: metastatic disease, lymphoma, and myeloma. In young patients with multifocal disease the differential diagnosis includes brown tumor, Langerhans cell histiocytosis, and fibrous dysplasia. The differential diagnosis for solitary lesions includes fibrous dysplasia or sarcomas such as Ewing's sarcoma, osteosarcoma, and fibrosarcoma (5). 


\section{Clinical presentation}

Review of the literature identified no clear correlation with age and sex in spinal EHE. In the present review of spinal EHE, the average age of onset for the 55 cases that was reported in the literature as well as our case was 39 years (range, 16 to 74 years). Both genders can be involved; however, it is slightly more common in males. Of all 55 cases we reviewed as well as our case, 31 of patients were male and 25 of them were female. Our review of literature is summarized in (Table 1).

From the literature, lesions were limited to one level of the spine in 31 patients and multiple levels in 25 patients. In our review, the most common region of involvement is the thoracic spine. Lesions were distributed in cervical spine in 14 cases, thoracic spine in 29 cases, lumbar spine in 18 cases, and sacral spine in 3 cases (Table 1).

Focal neck or back pain is the most common presentations of spinal EHE. In three large case series, all patients presented with local neck or back pain $(1,5,14)$. Pathological fractures associated with back pain have also been described as a common presentation. In our case, the patient presented with local back pain and pathological fracture on radiological images. Luzzati et al. (14) reported pathological fracture in eight out of ten cases in their series. Soft-tissue extensions can lead to neurologic compression, which result in neurologic symptoms such as paresthesia, weakness, and paraplegia $(1,5,7,8,15,29,32-34,36,41-45)$.

\section{Treatment}

Since spinal EHE is a rare disease and its natural history is unpredictable, there is no standard of care for treatment. Treatment options include preoperative embolization, surgical resection which can be followed by radiotherapy and/or chemotherapy. Therapeutic management should begin with biopsy, CT guided biopsy is preferred as a laminectomy and an open biopsy may make it difficult to achieve a wide resection afterwards (14). Spinal EHE is a very vascular tumor which can be associated with significant intraoperative bleeding. Termination of surgery secondary to extensive intraoperative bleeding has been reported in one patient with spinal hemangioendothelioma who did not undergo preoperative embolization (46). Therefore, preoperative embolization is recommended to decrease the risk of intraoperative bleeding, improve the surgical field of view, and to "shrink" (i.e., devascularize) the tumor $(5,13,15,43,47)$.
Surgical management is very challenging since the tumor is highly vascular. The extent of surgery can be wide margin, marginal, or intralesional resection. Luzzati et al. (14) reported the largest case series of ten patients with spinal EHE; in their series, patients who had undergone wide or marginal resection had a better prognosis. The average follow-up duration was 84 months, during that period they observed two cases with local recurrence; both cases had previous intralesional surgery at different hospitals. One of the two patients underwent wide surgical resection and was alive at a long follow-up and was free of disease. The other patient was treated with intralesional surgeries and was alive after 10 months with local disease. They reported two mortalities from metastatic disease (Table 1) (14). Ma et al. (1) reported five patients with spinal EHE. The average follow-up duration was 47 months, wide surgical resection was performed in four of the five cases, limited laminectomy and cytoreductive surgery were performed in one case. The patient who underwent laminectomy had a progression of local disease, metastasis at 24 months after surgery, and died 10 months after that. No other report of mortality, recurrence, or metastasis in their series (Table 1) (1). Four out of the five cases in their series were treated with radiotherapy after surgery; however, predicting the role of radiotherapy in such cases is still difficult as the data is limited. According to the literature, wide resection (i.e., complete resection) should be used to achieve a good outcome, however, larger studies are needed to draw a definitive conclusion.

Patients may benefit from spinal stabilization following surgical resection to prevent pain and spinal instability. In one case series, three out of six cases who had vertebral collapse but no spinal stabilization, had back pain on followup (5). Sebastian et al. (27) described a novel treatment for spinal EHE, using minimally invasive technique without the need for fusion to avoid the morbidity of wide resection. They did preoperative cryoablation followed by partial corpectomy, tumor resection, allograft reconstruction of the vertebrae, and adjuvant interferon and bisphosphonate therapy. At 3.5 years' follow-up, the patient is pain-free, with no further progression or regression of the disease, and no signs of instability (27).

According to few reports in literatures, radiotherapy for spinal EHE is used in partially excised lesions and when it is difficult to access the lesion $(5,16,43,46)$. Campanacci et al. recommended the use of postoperative radiotherapy to decrease the risk of local recurrence after surgery (48). In the study reported by Kelahan et al., one patient had 


\begin{tabular}{|c|c|c|c|c|c|c|}
\hline References & Year & Age/sex & Location & Presentation & Management & FU period/outcome \\
\hline Present case & 2016 & $34 / \mathrm{M}$ & T5 & Back pain & $\mathrm{IS}+\mathrm{RT}$ & $3 \mathrm{~m} / \mathrm{improved}$ \\
\hline Kelahan et al. (13) & 2015 & $67 / \mathrm{M}$ & L4, L5, S1, S2 & Back pain & $\mathrm{IS}+\mathrm{RT}$ & $3 \mathrm{~m} /$ metastasis to $\mathrm{T} 6$ \\
\hline Sebastian et al. (27) & 2015 & $18 / \mathrm{M}$ & L2, T9, C7 & Back pain & IS & $\begin{array}{l}42 \mathrm{~m} / \text { no recurrence at } \mathrm{L} 2, \\
\text { stable disease at T9 and } \mathrm{C} 7\end{array}$ \\
\hline \multirow[t]{10}{*}{ Luzzati et al. (14) } & 2015 & $47 / F$ & L1 & Back pain and fracture & MM & 105 m/NED \\
\hline & & $28 / F$ & $\mathrm{~T} 4, \mathrm{~T} 5$ & Back pain and fracture & MM & 109 m/died \\
\hline & & $41 / \mathrm{M}$ & T1 & Back pain & MM & $36 \mathrm{~m} /$ died-lung metastasis \\
\hline & & $66 / F$ & T5, T6 & Back pain and fracture & MM & 124 m/NED \\
\hline & & $17 / F$ & T8 & Back pain & WS & $90 \mathrm{~m} / \mathrm{NED}$ \\
\hline & & $62 / F$ & L4, L5, S1, L & Back pain and fracture & IS & $14 \mathrm{~m} /$ died-metastasis \\
\hline & & $50 / F$ & L1 & Back pain and fracture & WS & $194 \mathrm{~m} / \mathrm{NED}$ \\
\hline & & $41 / \mathrm{M}$ & T5 & Back pain and fracture & MM & $30 \mathrm{~m} / \mathrm{NED}$ \\
\hline & & $53 / \mathrm{M}$ & $\mathrm{T} 1, \mathrm{~T} 2, \mathrm{~T} 3$ & Back pain and fracture & MM & $61 \mathrm{~m} /$ local disease \\
\hline & & $40 / \mathrm{M}$ & $\mathrm{T} 7$ & Back pain and fracture & MM & $124 \mathrm{~m} / \mathrm{NED}$ \\
\hline Sardaro et al. (28) & 2014 & $46 / F$ & L3, L4 & Back pain & RT (30 Gy) & $12 \mathrm{~m} /$ died \\
\hline Pérez-Prieto et al. (29) & 2014 & $63 / \mathrm{M}$ & C5 & R upper limb weakness & WS + RT (46 Gy) & $30 \mathrm{~m} / \mathrm{NED}$ \\
\hline Guy et al. (4) & 2014 & $48 / F$ & T10 & $\begin{array}{l}\text { Initially asymptomatic then } \\
\text { back pain }\end{array}$ & RT (54 Gy) & $18 \mathrm{~m} / \mathrm{stable}$ \\
\hline Matamalas et al. (30) & 2014 & $58 / F$ & $\mathrm{C} 2, \mathrm{C} 3$ & Anemia and cervical pain & $\mathrm{IS}+\mathrm{RT}+\mathrm{CT}$ & $24 \mathrm{~m} /$ metastasis \\
\hline Yim et al. (31) & 2012 & $55 / \mathrm{M}$ & $\mathrm{C} 2, \mathrm{C} 4$ & Neck pain & RT (55 Gy) & $120 \mathrm{~m} / \mathrm{NED}$ \\
\hline Kerry et al. (3) & 2012 & $25 / M$ & $\begin{array}{l}\text { T7, lung, pleural, } \\
\text { lymphonodular } \\
\text { and cutaneous } \\
\text { metastasis }\end{array}$ & Back pain & $\begin{array}{l}\text { IS + resection of } \\
\text { lung metastasis, } \\
\text { RT, CT }\end{array}$ & $2 \mathrm{~m} /$ died \\
\hline \multirow[t]{5}{*}{ Ma et al. (1) } & 2011 & $20 / F$ & C5, C6 & Neck pain & $\mathrm{WS}+\mathrm{RT}^{*}$ & $72 \mathrm{~m} / \mathrm{NED}$ \\
\hline & & $42 / \mathrm{M}$ & T3 & Back pain & $\mathrm{WS}+\mathrm{RT}^{*}$ & $58 \mathrm{~m} / \mathrm{NED}$ \\
\hline & & $50 / \mathrm{M}$ & T8, T9 & Back pain & WS & $48 \mathrm{~m} / \mathrm{NED}$ \\
\hline & & $22 / F$ & T9 & Back pain & $\mathrm{IS}+\mathrm{RT}^{*}$ & $34 \mathrm{~m} /$ died-metastasis \\
\hline & & $40 / F$ & L1 & Back pain, paresthesia & $\mathrm{WS}+\mathrm{RT}^{*}$ & $25 \mathrm{~m} / \mathrm{NED}$ \\
\hline Neves et al. (32) & 2010 & $51 / F$ & L1 & Back pain, paraplegia & WS & $71 \mathrm{~m} / \mathrm{NED}$ \\
\hline Wang et al. (33) & 2009 & $22 / F$ & T12 & Back pain, paresthesia & WS & - \\
\hline \multirow[t]{2}{*}{ Kopniczky et al. (34) } & 2008 & 48/M & $\mathrm{C} 3, \mathrm{C} 4$ & $\begin{array}{l}\text { Numbness, paresthesia in } \\
\text { the right upper limb }\end{array}$ & IS + RT (55 Gy) & $36 \mathrm{~m} / \mathrm{NED}$ \\
\hline & & $43 / \mathrm{M}$ & $\mathrm{T} 10$ & Back pain, paraparesis & WS & - \\
\hline Christodoulou et al. (8) & 2008 & $41 / \mathrm{M}$ & L2 & Back pain, numbness & WS & $32 \mathrm{~m} / \mathrm{NED}$ \\
\hline Bölke et al. (35) & 2006 & $47 / \mathrm{M}$ & $\begin{array}{l}\text { Thoracic, lumbar, } \\
\text { sacral spine, and } \\
\text { other multiple } \\
\text { sites }\end{array}$ & $\begin{array}{l}\text { Abdominal and back } \\
\text { pain }\end{array}$ & CT & -/died \\
\hline Gokhan et al. (36) & 2006 & $30 / \mathrm{M}$ & L1, L2 & $\begin{array}{l}\text { Back pain, difficulty } \\
\text { in walking, urinary } \\
\text { incontinence, and } \\
\text { numbness. }\end{array}$ & WS & $8 \mathrm{~m} / \mathrm{NED}$ \\
\hline
\end{tabular}

Table 1 (continued) 


\begin{tabular}{|c|c|c|c|c|c|c|}
\hline References & Year & Age/sex & Location & Presentation & Management & FU period/outcome \\
\hline Aquilina et al. (37) & 2005 & $17 / \mathrm{M}$ & $\mathrm{T} 10$ & Back pain & WS + RT (30 Gy) & $16 \mathrm{~m} /$ local relapse \\
\hline Hisaoka et al. (7) & 2005 & $50 / F$ & C1, C4 & \multicolumn{2}{|l|}{$\begin{array}{l}\text { Dizziness, numbness in thelS } \\
\text { right side }\end{array}$} & $12 \mathrm{~m} /$ died-metastasis \\
\hline Adler et al. (38) & 2005 & $16 / \mathrm{M}$ & $\begin{array}{l}\text { C1, C2, C6, C7 } \\
\text { and other multiple } \\
\text { sites }\end{array}$ & Syncope and headaches & IS & -/died \\
\hline $\begin{array}{l}\text { Themistocleous } \\
\text { et al. (15) }\end{array}$ & 2005 & $23 / F$ & T8 & Back pain, paraplegia & IS + RT (55 Gy) & $26 \mathrm{~m} / \mathrm{NED}$ \\
\hline \multirow{6}{*}{ Aflatoon et al. (5) } & & $29 / F$ & L3 & Back pain & IS & $108 \mathrm{~m} / \mathrm{NED}$ \\
\hline & & $25 / F$ & L5 & \multicolumn{2}{|c|}{ Pain and paresthesia in legIS + RT } & 120 m/NED, back pain \\
\hline & & $21 / \mathrm{M}$ & $\mathrm{T} 12$ & Back pain & WS + RT (40 Gy) & $\begin{array}{l}\text {-/died-post-irradiation } \\
\text { sarcoma }\end{array}$ \\
\hline & & $27 / F$ & L2 & Back pain & $\mathrm{RT}$ & -/back pain \\
\hline & & $29 / F$ & L4 & Back pain & WS & $60 \mathrm{~m} / \mathrm{NED}$ \\
\hline & & $28 / \mathrm{M}$ & T1, T2 & Back pain and paresis & $I S+R T$ & $4 \mathrm{~m} /$ died-metastasis \\
\hline Casey et al. (39) & 2004 & $60 / \mathrm{M}$ & $\mathrm{C} 2, \mathrm{C} 4$ & Neck pain & IS & $24 \mathrm{~m} / \mathrm{stable}$ \\
\hline Evans et al. (40) & 2003 & $25 / \mathrm{M}$ & T11, skull, L femur & Back pain & IS & $60 \mathrm{~m} /$ died-metastasis \\
\hline Brennan et al. (43) & 2001 & $58 / \mathrm{M}$ & C5, C6, C7 & Neck pain, myelopathy & IS & $6 \mathrm{~m} /$ myelopathy improved \\
\hline Boutin et al. (25) & 1996 & $24 / \mathrm{M}$ & $\begin{array}{l}\text { Cervical, thoracic, } \\
\text { and lumbar spine }\end{array}$ & Back pain, neck stiffness & $\begin{array}{l}\mathrm{RT}(3,750 \text { cGy })+ \\
\text { CT }\end{array}$ & 36 m/asymptomatic \\
\hline Ellis et al. (11) & 1996 & $31 / F$ & L2 & Back pain & WS & $18 \mathrm{~m} / \mathrm{NED}$ \\
\hline Abrahams et al. (44) & 1992 & $34 / \mathrm{M}$ & T3 & Back pain, numbness & & - \\
\hline \multirow[t]{3}{*}{ Tsuneyoshi et al. (16) } & 1986 & $26 / \mathrm{M}$ & $\mathrm{T} 11$ & Back pain & $W S+R T$ & $20 \mathrm{~m} /$ metastasis \\
\hline & & $16 / \mathrm{M}$ & T9 & Back pain & IS & 48 m/asymptomatic \\
\hline & & $73 / \mathrm{M}$ & T10, L1 & Back pain & IS + RT & - \\
\hline Maruyama et al. (45) & 1985 & $43 / F$ & T3 & $\begin{array}{l}\text { Back pain, neurological } \\
\text { disturbances }\end{array}$ & $W S+R T$ & $\begin{array}{l}1 \mathrm{~m} / \text { neurological disturbances } \\
\text { disappeared }\end{array}$ \\
\hline
\end{tabular}

*, total dose of radiotherapy ranged from 40 to 60 Gy. EHE, epithelioid hemangioendothelioma; M, male; F, female; L, lumbar; T, thoracic; S, sacral; C, cervical; RT, radiation therapy; CT, chemotherapy; WS, wide surgery; IS, intralesional surgery; m, month; NED, no evidence of disease; FU, follow-up. 
local progression of spinal EHE two months after surgical stabilization. For that reason, the patient subsequently was treated with localized radiotherapy, at 3 months follow-up there was significant regression of the epidural tumor (13). Sardaro et al. reported a patient who was treated with radiotherapy alone which result in pain control and no progression of bone disease by 1-year follow-up examination, however, the patient died after that because of systemic disease (28). Ma et al. (1) reported four patients who underwent surgical resection followed by radiotherapy; in three cases recurrence could not be detected after a long follow-up period. Radiation induced sarcoma has been documented in a patient with spinal hemangioendothelioma who was treated with radiotherapy (5). The risk is directly related to the dose of radiation, with the dose range of 40 to $70 \mathrm{~Gy}$, the risk is less than $1 \%$ (49).

The role of and timing of chemotherapy is still not defined $(11,50)$. Interferon $2 \alpha$ or carboplatin plus etoposide have been used for patients with widespread disease but the evidence is not clear (28). No definitive conclusions about the use of chemotherapy and radiotherapy can be made until larger studies can be analyzed.

\section{Conclusions}

Our review highlights the diagnosis, clinical presentation, and treatment of spinal EHE. Spinal EHE is a quite rare disease with few case reports and series reported in the literature. We identified no clear correlation with patient's age and sex in spinal EHE. Both genders can be involved; however, it is slightly more common in males. According to the literature, complete resection is associated with good outcome. Radiotherapy is used in partially excised lesions; however, the role of radiotherapy as primary treatment is not yet defined. Further studies are required to develop a treatment algorithm for this rare spinal tumor.

\section{Acknowledgements}

None.

\section{Footnote}

Conflicts of Interest: The authors have no conflicts of interest to declare.

Informed Consent: Written informed consent was obtained from the patient for publication of this manuscript and any accompanying images.

\section{References}

1. Ma J, Wang L, Mo W, et al. Epithelioid hemangioendotheliomas of the spine: clinical characters with middle and long-term follow-up under surgical treatments. Eur Spine J 2011;20:1371-6.

2. Weiss SW, Enzinger FM. Epithelioid hemangioendothelioma: a vascular tumor often mistaken for a carcinoma. Cancer 1982;50:970-81.

3. Kerry G, Marx O, Kraus D, et al. Multifocal epithelioid hemangioendothelioma derived from the spine region: case report and literature review. Case Rep Oncol 2012;5:91-8.

4. Guy JB, Trone JC, Chargari C, et al. Epithelioid hemangioendothelioma of the spine treated with RapidArc volumetric-modulated radiotherapy. Med Dosim 2014;39:242-5.

5. Aflatoon K, Staals E, Bertoni F, et al. Hemangioendothelioma of the spine. Clin Orthop Relat Res 2004;(418):191-7.

6. Hart J, Mandavilli S. Epithelioid angiosarcoma: a brief diagnostic review and differential diagnosis. Arch Pathol Lab Med 2011;135:268-72.

7. Hisaoka M, Okamoto S, Aoki T, et al. Spinal epithelioid hemangioendothelioma with epithelioid angiosarcomatous areas. Skeletal Radiol 2005;34:745-9.

8. Christodoulou A, Symeonidis PD, Kapoutsis D, et al. Primary epithelioid hemangioendothelioma of the lumbar spine. Spine J 2008;8:385-90.

9. Flucke U, Vogels RJ, de Saint Aubain Somerhausen N, et al. Epithelioid Hemangioendothelioma: clinicopathologic, immunhistochemical, and molecular genetic analysis of 39 cases. Diagn Pathol 2014;9:131.

10. Mentzel T, Beham A, Calonje E, et al. Epithelioid hemangioendothelioma of skin and soft tissues: clinicopathologic and immunohistochemical study of 30 cases. Am J Surg Pathol 1997;21:363-74.

11. Ellis TS, Schwartz A, Starr JK, et al. Epithelioid hemangioendothelioma of the lumbar vertebral column: case report and review of literature. Neurosurgery 1996;38:402-7.

12. Errani C, Vanel D, Gambarotti M, et al. Vascular bone tumors: a proposal of a classification based on clinicopathological, radiographic and genetic features. Skeletal Radiol 2012;41:1495-507. 
13. Kelahan LC, Sandhu FA, Sayah A. Multifocal hemangioendothelioma of the lumbar spine and response to surgical resection and radiation. Spine J 2015;15:e49-56.

14. Luzzati A, Gagliano F, Perrucchini G, et al. Epithelioid hemangioendothelioma of the spine: results at seven years of average follow-up in a series of 10 cases surgically treated and a review of literature. Eur Spine J 2015;24:2156-64.

15. Themistocleous GS, Papagelopoulos PJ, Petraki KD, et al. A 23-year-old woman with complete paraplegia and anesthesia below the T8 level. Clin Orthop Relat Res 2005:258-65.

16. Tsuneyoshi M, Dorfman HD, Bauer TW. Epithelioid hemangioendothelioma of bone. A clinicopathologic, ultrastructural, and immunohistochemical study. Am J Surg Pathol 1986;10:754-64.

17. Traweek ST, Kandalaft PL, Mehta P, et al. The human hematopoietic progenitor cell antigen (CD34) in vascular neoplasia. Am J Clin Pathol 1991;96:25-31.

18. Marthya A, Patinharayil G, Puthezeth K, et al. Multicentric epithelioid angiosarcoma of the spine: a case report of a rare bone tumor. Spine J 2007;7:716-9.

19. Rossi S, Orvieto E, Furlanetto A, et al. Utility of the immunohistochemical detection of FLI-1 expression in round cell and vascular neoplasm using a monoclonal antibody. Mod Pathol 2004;17:547-52.

20. Miettinen M, Wang ZF, Paetau A, et al. ERG transcription factor as an immunohistochemical marker for vascular endothelial tumors and prostatic carcinoma. Am J Surg Pathol 2011;35:432-41.

21. Ohsie SJ, Sarantopoulos GP, Cochran AJ, et al. Immunohistochemical characteristics of melanoma. J Cutan Pathol 2008;35:433-44.

22. Gill R, O'Donnell RJ, Horvai A. Utility of immunohistochemistry for endothelial markers in distinguishing epithelioid hemangioendothelioma from carcinoma metastatic to bone. Arch Pathol Lab Med 2009; 133:967-72.

23. Errani C, Zhang L, Sung YS, et al. A Novel WWTR1CAMTA1 Gene Fusion Is a Consistent Abnormality in Epithelioid Hemangioendothelioma of Different Anatomic Sites. Genes Chromosomes Cancer 2011;50:644-53.

24. Doyle LA, Fletcher CD, Hornick JL. Nuclear Expression of CAMTA1 Distinguishes Epithelioid Hemangioendothelioma From Histologic Mimics. Am J Surg Pathol 2016;40:94-102.

25. Boutin RD, Spaeth HJ, Mangalik A, et al. Epithelioid hemangioendothelioma of bone. Skeletal Radiol
1996;25:391-5.

26. Wold LE, Unni KK, Beabout JW, et al. Hemangioendothelial sarcoma of bone. Am J Surg Pathol 1982;6:59-70.

27. Sebastian AS, Adair MJ, Morris JM, et al. Minimally invasive treatment of a painful osteolytic lumbar lesion secondary to epithelioid hemangioendothelioma. Global Spine J 2015;5:135-9.

28. Sardaro A, Bardoscia L, Petruzzelli MF, et al. Pulmonary epithelioid hemangioendothelioma presenting with vertebral metastases: a case report. J Med Case Rep 2014;8:201.

29. Pérez-Prieto D, Lloreta J, Ramírez M. Epithelioid hemangioendothelioma of the cervical spine successfully treated with subtotal resection and radiotherapy. Eur Orthop Traumatol 2014;5:375-8.

30. Matamalas A, Gargallo A, Porcel JA, et al. Cervical spine epithelioid hemangioendothelioma: case report. Eur Rev Med Pharmacol Sci 2014;18:72-5.

31. Yim KL, Sumathi VP, Spooner D. Radiotherapy as an effective primary treatment for epithelioid haemangioendothelioma of the cervical spine. Anticancer Res 2012;32:4597-600.

32. Neves N, Lima-Rodrigues F, Ribeiro-Silva M, et al. Epithelioid Hemangioendothelioma Presenting as a Vertebral Fracture. Acta Reumatologica Portuguesa 2010;35:370-4.

33. Wang CG, Jia NY, Yu HY, et al. Epithelioid hemangioendothelioma of thoracic vertebra: a case report (2008: 11b). Eur Radiol 2009;19:517-20.

34. Kopniczky Z, Tsimpas A, Lawson DD, et al. Epithelioid hemangioendothelioma of the spine: report of two cases and review of the literature. Br J Neurosurg 2008;22:793-7.

35. Bölke E, Gripp S, Peiper M, et al. Multifocal epithelioid hemangioendothelioma: case report of a clinical chamaeleon. Eur J Med Res 2006;11:462-6.

36. Gokhan GA, Akyuz M, Gurer IE, et al. Epithelioid hemangioendothelioma derived from the spine region: case report and review of the literature. Wien Klin Wochenschr 2006;118:358-61.

37. Aquilina K, Lim C, Kamel MH, et al. Epithelioid hemangioendothelioma of the spine. Report of two cases. J Neurosurg Spine 2005;3:393-9.

38. Adler B, Naheedy J, Yeager N, et al. Multifocal epithelioid hemangioendothelioma in a 16-year-old boy. Pediatr Radiol 2005;35:1014-8.

39. Casey MC, Lim C, Hickey MC. Case of the month: an unusual cause of neck pain. Br J Radiol 2004;77:539-40. 
40. Evans HL, Raymond AK, Ayala AG. Vascular tumors of bone: A study of 17 cases other than ordinary hemangioma, with an evaluation of the relationship of hemangioendothelioma of bone to epithelioid hemangioma, epithelioid hemangioendothelioma, and high-grade angiosarcoma. Hum Pathol 2003;34:680-9.

41. Faust J, Schmidt M, Eysel P, et al. Epithelioid hemangioendothelioma of the spine. Med Klin (Munich) 2001;96:740-4.

42. Chau YP, Chan AC, Wong CC. Pathologic quiz case: lytic lesion in the vertebra of a 17-year-old adolescent girl. Arch Pathol Lab Med 2001;125:1611-2.

43. Brennan JW, Midha R, Ang LC, et al. Epithelioid hemangioendothelioma of the spine presenting as cervical myelopathy: case report. Neurosurgery 2001;48:1166-9.

44. Abrahams TG, Bula W, Jones M. Epithelioid hemangioendothelioma of bone. A report of two cases and review of the literature. Skeletal Radiol 1992;21:509-13.

45. Maruyama N, Kumagai Y, Ishida Y, et al. Epithelioid

Cite this article as: Albakr A, Schell M, Drew B, Cenic A. Epithelioid hemangioendothelioma of the spine: case report and review of the literature. J Spine Surg 2017;3(2):250-259. doi: 10.21037 /jss.2017.05.05 haemangioendothelioma of the bone tissue. Virchows Arch A Pathol Anat Histopathol 1985;407:159-65.

46. Sybert DR, Steffee AD, Keppler L, et al. Seven-year follow-up of vertebral excision and reconstruction for malignant hemangioendothelioma of bone. Spine (Phila Pa 1976) 1995;20:841-4.

47. Marks DS, Thomas AM, Thompson AG, et al. Surgical management of haemangioendothelioma of the spine. Eur Spine J 1995;4:186-90.

48. Campanacci M, Boriani S, Giunti A. Hemangioendothelioma of bone: a study of 29 cases. Cancer 1980;46:804-14.

49. Tountas AA, Fornasier VL, Harwood AR, et al. Postirradiation sarcoma of bone: a perspective. Cancer 1979;43:182-7.

50. Kleer CG, Unni KK, McLeod RA. Epithelioid hemangioendothelioma of bone. Am J Surg Pathol 1996;20:1301-11. 